\title{
Shift Work and Fatigue
}

\author{
${ }^{1}$ Salma Ummul, ${ }^{2}$ Kameswara Rao K \\ ${ }^{1}$ Faculty, Al-Aman College of Engineering, Gudilova, Visakhapatnam, India. \\ 2 Professor, Department of Environmental Sciences, Andhra University, Andhra Pradesh, India
}

\begin{abstract}
With the vital need to extend services or enable uninterrupted productivity, several millions had to work in shifts varying in length of time for a greater part of their age. Interest in the effects of shift work on people has developed because many experts have blamed rotating shifts for human error connected to a number of accidents and catastrophes. Together with the alarming relationship of shift work to fatigue, performance, accidents and chronic heart disease, there is reason to believe that shift work may become a major challenge for the employer, employee and occupational health professionals. Thus, work schedules and work load factors need to be examined in combination to obtain a realistic picture of the effects of shift work on fatigue
\end{abstract}

Keywords: Shift work, Stress Fatigue Biological rhythm, Circadian Clock.

\section{Introduction}

Today shift work has become a routine feature in industries, hospitals and many other essential sectors (Knutsson, 1989; Tepas et al, 1993; Gupta et al, 1997; Chandrawanshi and Pati, 2000) and will be absolutely inevitable in future if the present rate of growth and development in industries are to continue.Many industrialized countries introduced and adopted shift work system with a view to optimize utilization of human resources and to ensure continuity in operation of industries and various other production houses.

According to the International Labour Office, shift work is defined as a method of work organization under which groups or crews of workers succeed each other at the same work station to perform the same operations each crew working a certain schedule or shift so that the undertaking can operate longer than the stipulated weekly hours for any worker.

Interest in the effects of shift work on people has developed because many experts have blamed rotating shifts for human error and it to a connected to a number of accidents and catastrophes. There is also sufficient evidence to prove that rotational shift work affects human health and performance by disrupting circadian rhythms and by causing numerous alterations in human behavior and physiology.

The word 'fatigue is a term applied to a wide diversity of conditions and results from most occupational tasks, due to more subtle psycho-physiological processes (Pheasant, 1991). Fatigue is the feeling of abnormal tiredness, lethargy, loss of drive and merges into a number of others, which are equally difficult to define such as stress, depression etc. These conditions are subjective, behavioral and physiological. .

Some studies have been conducted to assess the fatigue as a result of shift rotation and sleep on shift working nurses and found a strong relation between the sleep disturbances and fatigue (Fugiwara, 1992; Gold et al., 1992). Further, fatigue was found to enhance common infections (Mohren et al, 2002). The poorly adapted night workers suffers from a potentially progressive state of chronic fatigue, which may be manifest in to episodes of irritability, loss of drive, depression, loss of appetite, constipation and other disturbances (Pheasant, 1991). Together with the alarming relationship of shift work to fatigue, performance, accidents and chronic heart disease, there is reason to believe that shift work may become a major challenge for the employer, employee and occupational health professionals.

Brain and body functions slow down during the nighttime and early morning hours. Working at night makes it difficult to get enough sleep. . The combination of sleep loss and working at the body's low point can cause excessive fatigue and sleepiness. This makes more difficult to perform well, which increases the risk of accidents (Madide, 2003). The accidents at Chernobyl and Three Mile Island occurred, around 01:00 hrs and the Bhopal disaster also occurred during the hours of night shift.

Thus, work schedules and work load factors need to be examined in combination to obtain a realistic picture of the effects of shift work on fatigue as was reported by Rosa (2000). Fatigue and insomnia are considered as the primary symptoms for the disturbances in the biological clocks or the circadian rhythms.

In India, the adversaries being faced by the shift workers have not received much attention from the researchers and requires a systematic documentation of the studies on the impacts of the altered biological rhythms on the health, social and domestic well being of the workers, along with the public safety.

Fatigue in rail transportation is a safety question. Lack of alertness was the most important single contributor for accidents and near accidents in a recent analysis (Edkins and Pollock, 1997). 
In view of this dearth, the present study is contemplated and focuses on the shift workers in Railways, perhaps the largest group under a single employer in India.

The present work entitled "Shift work and Fatigue" was carried out during June 2006 to February 2009. The staff of the E.Co. Division of the Indian Railways, who are working on shift duties constituted the main target group of the study.

In view of the above, the present work entitled "Shift work and Fatigue" has been contemplated with the following objectives:

1. To understand the occupational health problems among shift staff of different age groups with varying service experience;

2. To identify the different health disorders or diseases associated with the shift staff and the incidences of these health problems;

3. To assess the different types of stress associated with the shift work and understand the impacts on health;

4. To evaluate the present shift pattern with special reference to their impacts on health and to suggest the optimal pattern.

\section{Methodology}

The study followed "Syndrome Approach" to realize the objectives of the study, by adopting a combination of the methods of obtaining data on the study respondents. The focus of the study being the health problems associated with the shift work, sampling was carried out by selecting the employees.

The Standard Shift Work Index developed by the Shift work Research Team MRC/ERSC Social and Applied Psychology Unit was used in the present study with few modifications to suit the local conditions. This Shift Work Index is a questionnaire which aims to identify the shift schedules, sleep habits, eating patterns if any psychological effects for an initial survey of the health which might be expected to increase or decrease the effects on health. The questionnaire in specific identifies to which type of shift pattern the employee belongs and the nature of duties, work load etc. The identification of sleep habits to assess the extent to which sleep is disturbed depending on which shift he has been or is about to work and as such the respondent tries to rank different stress indicators related to sleeplessness, fatigue, anxiety, anger, depression and mental states and their frequency as they perceive. The distribution of the different age-sex groups in the sample reflected their proportional distribution among the railway employees of Visakhapatnam division. About 3-5\% of the population was selected as samples that constitute 300 individuals.

\section{Results}

\subsection{Distribution of Age Groups:}

The population was stratified in to four Age groups, with an interval of 10 years. On the whole, about $228(76 \%)$ of the individuals were Men; and $72(24 \%)$ were women. Among different age groups, the gender composition varied and the women's ratio has declined in the higher age groups as indicated in Table 1

Table 1- Distribution of Age Groups

\begin{tabular}{|c|c|c|c|}
\hline No. & Age Group Name & Age in Years & Number Sampled \\
\hline 1. & AG-1 & Up to 30 & 120 \\
\hline 2. & AG-2 & 31 to 40 & 99 \\
\hline 3. & AG-3 & 41 to 50 & 56 \\
\hline 4. & AG-4 & 51 and above & 25 \\
\hline
\end{tabular}

\subsection{Distribution of Employees Types:}

Of the 300 individuals examined in the study, Drivers (Loco Pilots) accounted for 41.33\%; Train Guards have accounted for $7 \%$ and the TTEs have accounted for $6.67 \%$. Thus, Travel mode shift employees altogether constitute 55\% of the total individuals examined. Stationary employees i.e. Technicians and Office staff accounted for $22.67 \%$ and $22.33 \%$, respectively. Symptoms of the health problems related to the disturbance of biological clock were considered.

\subsection{Incidence of Fatigue Stress:}

The incidence of Fatigue stress was found in $31.33 \%$ of the total respondents or $65.74 \%$ of the respondents identified as affected by the stress. Of the total affected, $23.40 \%$ were women and $76.60 \%$ were males.

Among the different employee types, OS and LP ranked $1^{\text {st }}(35.29 \%)$ and $2^{\text {nd }}(34.68 \%)$, respectively, followed by GD (33.33\%); TN (28.74\%) and TTE (15\%) only. It is alarming to note that among the fatigue affected, $88.85 \%$ were in the lower age groups (AG1 and AG2), which indicates that this group may have more health problems in the latter parts of their service.

Among the affected women, $90.91 \%$ were in the AG-1, while $4.55 \%$ each were in AG-2 and AG-3 groups, while there were none in AG-4. Among the affected Men, $34.72 \%$ were in AG-1; $41.67 \%$ were in AG-2; $18.06 \%$ were in AG-3 and $5.56 \%$ were in AG-4. 
Of the total affected, $45.74 \%$ were LPs, $25.53 \%$ were OSs, $18.09 \%$ were TNs, $7.45 \%$ were GDs and only $3.19 \%$ were TTEs. However, among the each employee type, a majority of the affected were in the lower age groups: Among the LPs, 83.72\% were in AG-1 and AG-2 groups. Among the GDs, 42.86\% were in AG-1; while among the TTEs and OSs, AG-1 group accounted for $66.67 \%$ and $70.83 \%$, respectively. While in TNs, the first three age groups had less variation among the incidence. However, among the affected belonging to AG-4 group, incidence among GDs was high (Fig. 3). The incidence of the Stress symptoms by Fatigue, and the distribution of the affected in various age-sex groups are presented in Table 2.

TABLE 2-- Stress symptoms by Fatigue in various age-sex groups

\begin{tabular}{|c|c|c|c|c|c|c|c|c|c|c|c|}
\hline \multirow{2}{*}{ S.No. } & \multirow{2}{*}{$\begin{array}{c}\text { Employee } \\
\text { Type }\end{array}$} & \multicolumn{2}{|c|}{ AG-1 } & \multicolumn{2}{|c|}{ AG-2 } & \multicolumn{2}{|c|}{ AG-3 } & \multicolumn{2}{|c|}{ AG-4 } & \multicolumn{2}{|c|}{ TOTAL } \\
\hline & & $\mathrm{N}$ & $\%$ & $\mathrm{~N}$ & $\%$ & $\mathrm{~N}$ & $\%$ & $\mathrm{~N}$ & $\%$ & $\mathrm{~N}$ & $\%$ \\
\hline 1 & LP & 18 & 41.86 & 18 & 41.86 & 6 & 13.95 & 1 & 2.33 & 43 & 45.74 \\
\hline 2 & GD & 3 & 42.86 & 0 & 0 & 2 & 28.57 & 2 & 28.57 & 7 & 7.45 \\
\hline 3 & TTE & 2 & 66.67 & 1 & 33.33 & 0 & 0 & 0 & 0 & 3 & 3.19 \\
\hline 4 & OS & 17 & 70.83 & 6 & 25.00 & 1 & 4.17 & 0 & 0 & 24 & 25.53 \\
\hline 5 & TN & 5 & 29.41 & 6 & 35.29 & 5 & 29.41 & 1 & 5.88 & 17 & 18.09 \\
\hline 6 & Total & 45 & 47.87 & 31 & 32.98 & 14 & 14.89 & 4 & 4.26 & & 94 \\
\hline
\end{tabular}

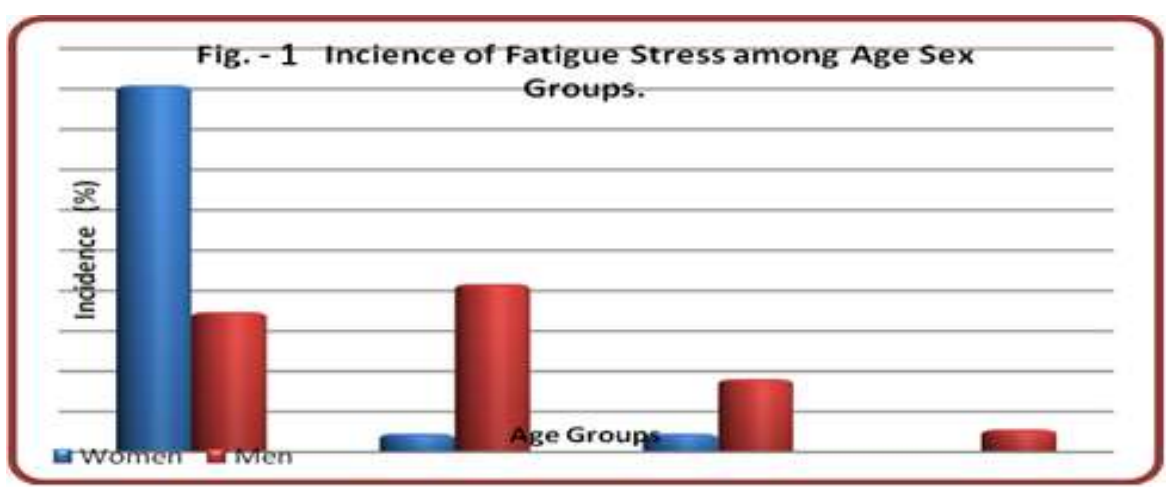

Fig, 1. Incidence of Fatigue Stress among Age Sex Groups

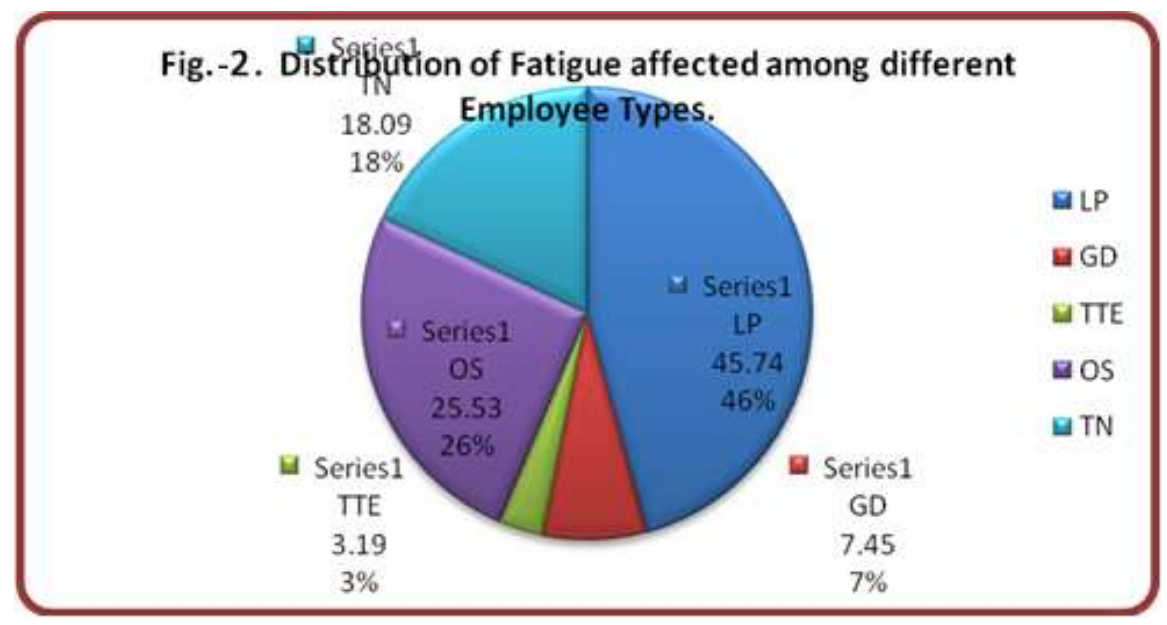

Fig.2. Distribution of Fatigue affected among different Employee Types 


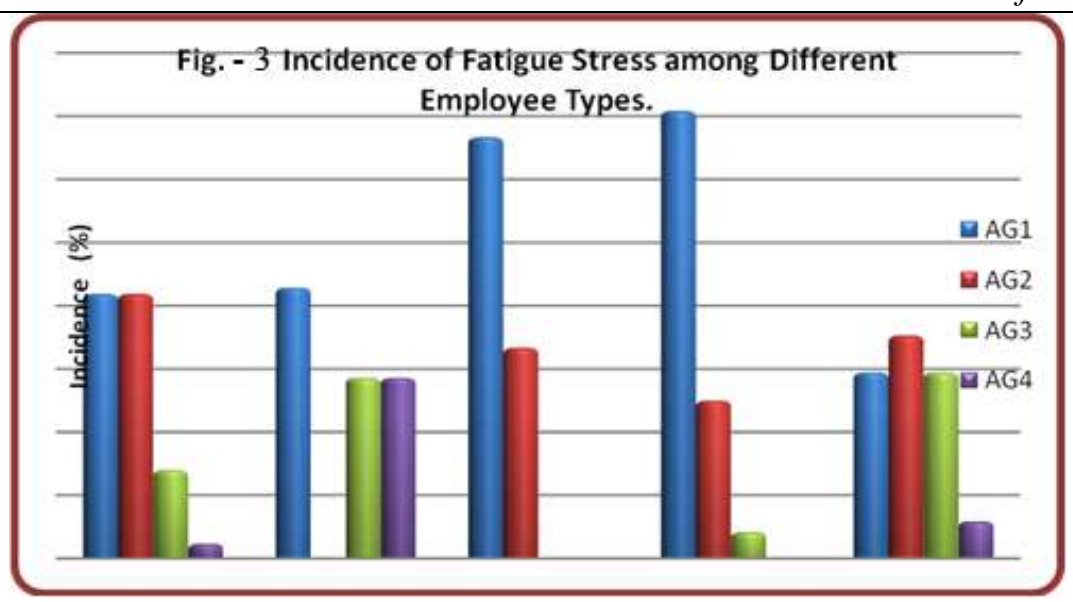

Fig. 3. Incidence of Fatigue Stress among Different Employee Types

\subsection{Discussion}

\section{Conclusion}

Shift workers had a significantly higher prevalence of fatigue. Higher fatigue levels are related to common infections as well. (Mohren et al, 2002). Among the six major stress symptoms studied, fatigue ranked first among the railway shift workers of the present study.

As was also reported by Andlauer, (1960); Koller, (1983), Bohle and Tilley, (1989) and Scott et al, (1997) increased stress due to sleeplessness and fatigue may lead to psychological problems. These may include irritation, anger, depression, and mental stress. All these symptoms were found to prevalent among the railway shift workers of the present study. Florez - Lozano, (1980) suggests that long working hours may cause irritability, physical and mental fatigue, excessive sleepiness, insomnia, and gastric ulcers and may also result in loss of attention and an increased number of accidents in the work place.

The basic principle underlying the rhythm variations is catabolism (the breaking down and release of energy) and readiness for action during the day, and anabolism (regeneration) and rest during the night. The combination of sleep loss and working at the body's low point can cause excessive fatigue and sleepiness. This makes more difficult to perform well, which increases the risk of accidents (Madide, 2003). Pheasant, (1991) states that the likelihood of error increases when the operator is under abnormal pressure of work, or when the working capacity is reduced because of fatigue. (Knutsson, 1989; Tepas et al, 1993; Gupta et al, 1997; Chandrawanshi and Pati, 2000). Although professional drivers have less fatigue related accidents than private drivers (Summala and Mikkola, 1994), fatigue prevention in road, air and marine transportation has become a major issue in many public and private transportation companies (Dinges, 1995). Accident reports also suggest that fatigue and poor shift schedules have occasionally been reported or identified as major contributors in serious rail accidents (Lauber and Kayten 1988; Moore-ede et al, 1996; Onnettomuustutkintakeskus, 1999).

\section{Summary}

With the alarming relationship of shift work to fatigue, performance, accidents and chronic heart disease, there is reason to believe that shift work may become a major challenge for the employer, employee and occupational health professionals. Further, it is essential that an ideal rotation of the shifts be adopted so as to reduce the sleeplessness and fatigue among the shift workers, ideally limiting the total work hours to less than $50 \mathrm{hrs} /$ week and night shift hours to less than $8 \mathrm{hrs} /$ week. Thus, the intensity of the stress reduces and the physical ability to cope up increases.

\section{Acknowledgements}

1. The author thanks the Almighty for giving her strength and health to do this research work until it is done.

2. The research work has been conducted in the Department of Environmental Sciences, Andhra University, Visakhapatnam, India and the author profoundly thanks Prof. K Kameswara Rao, her Research Guide for his expert guidance throughout the research work.

3. The author thanks all the authors referred in References for their valuable work which could help her in getting an insight in completing this research article.

4. The author expresses her deep sense of gratitude to Janab IH Farooqui, the Secretary \& Correspondent of Al-Aman College of Engineering for extending his support in completing this research work. 
5. The author is forever indebted to her father, Janab Haji Mohd. Younis Rizvi, mother, Mumtaz Begum, husband, Janab H Abdul Khader and thankful to the family members, without whose support and encouragement this research work would not have been completed.

6. The author thanks all her colleagues, shift staff for their kind help and support throughout the research work.

\section{References}

[1] Knutsson A1989Shift work and coronary heart disease. Scandinavian Journal of Social Medicine 44:1-36

[2] Tepas DI, Duchon JC, Gersten AH 1993 Shift work and the older worker. Experimental Aging Research 19:295-320

[3] Gupta S, Pati AK, Levi F. 1997Pattern of shift rota modulates oral temperature rhythm and sleep wakefulness profiles in shift workers. Journal of Biosciences 22:477-488

[4] Chandrawanshi A and Pati A K. 2000 Could Externally desynchronized Circadian Rhythm be resynchronized in Shift Workers? Biological Rhythm Research, 2000, Vol 31, No. 2, PP: 160176

[5] Pheasant, S.T. 1991Work and Health, Mac Millan Press, London, Ergonomics, pp.3-4, 156-157, 171-172, 185-188

[6] Fugiwara,S1992 Studies on fatigue and shift work in nurses. Sangyo-Igaku, 34:225-235

[7] Gold, D.R. Rogacz, D, Bock, Tosteson, T.D, Baum, T.M. Soeuzer, F.E. and Czeisler D.A. $1992 \quad$ Rotating shift work, sleep and accidents related to sleepiness in hospital nurses.Ann.J.Public Health, 82:1011-1014

[8] Mohren DCL, Swaen GMH, Kant IJ, Borm PJA, Galama JMD2002 Associations between common infections and fatigue in a Dutch working population: results of the Maastricht Cohort Study on Fatigue at work. Eur J Epidemiol. In press

[9] Madide S 2003 Effects of Night Shift Schedules on Nurses Working in a Private Hospital in South Africa

[10] Rosa, R.R 2000 Examining work schedules for fatigue: It's not just hours of work. In: Hancock PA, Desmond PA, eds. Stress, workload and fatigue. Mahwah: Lawrence Erlbaum Associates, 2000:513-28

[11] Edkins, G and Pollock, C 1997 The influence of sustained attention on railway accidents. Accident Anal. Prevention, , 29: 533 539

[12] Mohren D C L, Jansen N W H, Kant I J M,Galama J, Swaen G M H 2002 Prevalence of Common Infections Among Employees in different Work Schedules. CME Article /1 JOEM Vol 44, No.11

[13] Andlauer, P.I.1960 The effect of shift working on the workers' health. European Productivity Agency, TU Information Bulletin, 29

[14] Koller, M. 1983 Health risks related to shift work: Int Arch Occup Environ Health, v. 53, p. 59-75.

[15] Bohle P, Tilley AJ. 1989 The impact of night work on psychological well-being. Ergonomics. 1989; 32:1089-1099.

[16] Scott, A. J., Monk T. H., and Brink L. L 1997 Shift work as a risk factor for depression: A pilot study: International Journal of Occupational and Environmental Health, v. 3, p. 2-9

[17] Floreq - Lozano JA. 1980 Aspects psicofidiologicos da fadiga.Revista Brasileira de Saude Occupational, 29:19-23

[18] Summala, H and Mikkola, T. 1994 Fatal accidents among car and truck drivers; effects of fatigue, age, and alcohol consumption. Hum. Factors, , 36:315-326

[19] Dinges, D1995An overview of sleepiness and accidents. J.Sleep Res., , 4 (Suppl. 2); $15-22$

[20] Lauber and Kayten,L. 1988, Sleepiness, circadian dysrhytmia, and fatigue in transportation system accidents. Sleep, 11:503-512

[21] Moor-ede, M.,Mitchell, R.,Hietmann, A., Trutschel, U,Aquirre, A. and Hajarnavis H.Canalert 95.1996 Alertness Assurance in the Canadian Railways. Phase II Report. Circadian Technologies Inc., Cambridge, 1996

[22] Onnettomuustutkintakeskus. Trains colliding at Suonenjoki, $1999 \quad$ August 12, 1998 (in Finnish with an English abstract). Onnettomuustukintakeskus: Tutkintaselostus B1, Helsinki 